\title{
Os gêneros Apuleia, Dimorphandra, Tachigali (Caesalpinioideae), Bauhinia, Schnella (Cercidoideae), Copaifera, Hymenaea e Peltogyne (Detarioideae) (Leguminosae) no Parque Estadual da Serra Dourada, Goiás, Brasil
}

The genera Apuleia, Dimorphandra, Tachigali (Caesalpinioideae), Bauhinia, Schnella (Cercidoideae), Copaifera, Hymenaea e Peltogyne (Detarioideae) (Leguminosae) in the Serra Dourada State Park, Goiás, Brazil

\author{
Alessandro Oliveira de Souza ${ }^{1,2}$, Marcos José da Silva ${ }^{1} \&$ Murilo Melo Dantas ${ }^{1}$
}

\begin{abstract}
Resumo
Com o intuito de contribuir com o conhecimento das Leguminosae presentes na região Centro-Oeste do Brasil, onde trabalhos sobre a mesma são escassos, foi elaborado o levantamento taxonômico dos gêneros Apuleia, Bauhinia, Copaifera, Dimorphandra, Hymenaea, Peltogyne, Schnella e Tachigali no Parque Estadual da Serra Dourada (PESD). Foram reconhecidas 15 espécies. Bauhinia foi o gênero mais numeroso com seis espécies, seguido por Hymenaea e Tachigali com duas espécies cada. Apuleia, Copaifera, Dimorphandra, Schnella e Peltogyne mostraram-se monoespecíficos. É apresentada uma chave para identificação dos táxons, descrições com comentários sobre suas distribuições geográficas e ilustrações.
\end{abstract}

Palavras-chave: diversidade, endemismo, Fabaceae, flora do Cerrado.

\begin{abstract}
A taxonomic survey of the genera Apuleia, Bauhinia, Copaifera, Dimorphandra, Hymenaea, Peltogyne, Schnella and Tachigali in the Serra Dourada State Park (SDSP) was carried out in order to contribute to the knowledge of the Leguminosae present in the Central West region of Brazil, where studies on the family are scarce. Fifteen species were found. Bauhinia was the most numerous genus with six species, followed by Hymenaea and Tachigali with two species each. Apuleia, Copaifera, Dimorphandra, Schnella and Peltogyne were represented by only one species each. An identifcation key, illustration to the taxa, and comments on their geographical distribution are provided.
\end{abstract}

Key words: diversity, endemism, Fabacae, flora of the Cerrado.

\section{Introdução}

Leguminosae ou Fabaceae possui distribuição Pantropical, circunscreve 727 gêneros e cerca de 19.325 espécies (LPWG 2017), dos quais 222 e 2.835 , respectivamente, ocorrem no Brasil, onde a família figura como a de maior riqueza entre as Angiospermas (BFG 2015). Tradicionalmente, esta família compreendia as subfamílias Caesalpinioideae DC., Mimosoideae DC. e Papilionoideae L. (LPWG 2013), no entanto, sua circunscrição foi reformulada a partir dos estudos do LPWG (2017) e passou a incluir seis subfamílias: Caesalpinioideae, incluindo Mimosoideae (148 espécies e 4.400 gêneros), Cercidoideae (12 e 335); Detarioideae (84 e 760), Dialioideae (17 e 85); Duparquetioideae com apenas um gênero e uma espécie (Duparquetia orchidacea Baill.) e Papilionoideae (503 e 14.000), sendo as quatro primeiras e a última com distribuição Pantropical, e a quinta exclusiva da África.

Embora Leguminosae seja reconhecida pelos frutos predominantemente do tipo legume, gineceu monômero, folhas alternas, compostas por 1 a muitos folíolos e flores 5-meras, bissexuais com androceu diplostêmones, possui uma extraordinária diversidade de hábitos e aspectos de crescimentos, padrões de simetria ou assimetria florais, diversidade de compostos químicos e capacidade de colonizar distintos, incluindo hostis ambientes, dado a sua eficiente capacidade de associação com bactérias fixadoras de nitrogênio ou fungos micorrízicos, fatores que em conjunto possibilitou sua excelente

\footnotetext{
${ }^{1}$ Universidade Federal de Goiás, Inst. Ciências Biológicas, Depto. Botânica, Campus Samambaia II, C.P. 131, 74001-970, Goiânia, GO, Brasil.

${ }^{2}$ Autor para correspondência: alessandro341@hotmail.com
} 
irradiação adaptativa e lhe confere o status de terceira maior família de Angiospermas (Lewis et al. 2005; LPWG 2013, 2017).

O conhecimento taxonômico de Leguminosae como um todo no Brasil, ainda carece de incrementos, sobretudo, se considerarmos sua diversidade no país, onde a maioria das informações sobre a família ainda se encontra na obra Flora brasiliensis elaborada por Bentham (1860).

O estado de Goiás, se destaca por sua flora rica e com inúmeras espécies endêmicas (BFG 2015) e por possuir unidades de conservações que merecem ter sua flora melhor estudada. Uma dessas unidades é o Parque Estadual da Serra Dourada situado na região oeste de Goiás. O parque já foi alvo de alguns estudos florísticos, dos quais podemos citar para a família Asteraceae (Moreira \& Teles 2014; Guida \& Teles 2015), Euphorbiaceae (Júnior et al. 2013; Sodré et al. 2014) e Leguminosae (Dantas \& Silva 2013a; e Dantas \& Silva 2013b), estes dois últimos abordando dois gêneros, entre os mais numerosos de Leguminosae-Caesalpinioideae, que são Chamaecrista Moench. e Senna Mill., respectivamente.

A partir do exposto e visando contribuir com conhecimento da flora de Goiás objetivou-se realizar o tratamento taxonômico dos gêneros Apuleia Mart., Bauhinia L., Copaifera L., Dimorphandra Schott., Hymenaea L., Peltogyne Vogel, Schnella Raddi e Tachigali Aubl. (Leguminosae) no Parque Estadual da Serra Dourada.

\section{Material e Métodos}

O Parque Estadual da Serra Dourada (PESD) corresponde a Serra Dourada e possui superfície de $30.000,00$ ha abrangendo os municípios de Buriti de Goiás, Goiás e Mossâmedes (Figura 1) entre $16^{\circ} 00^{\prime}-16^{\circ} 04^{\prime}$ 'S e $50^{\circ} 30^{\prime} \mathrm{W}$ (Rizzo 1970). Abrange as formações de Floresta Estacional, Mata de Galeria, Cerrado sensu stricto (s.s.), Cerrado Rupestre, Campos limpos e solos variados com afloramentos rochosos. Possui clima Aw, com chuvas desde outubro a abril, temperatura média anual de $23,6^{\circ} \mathrm{C}$, e altitude entre 800-1080 m (Cochrane et al. 1985; Koppen 1948). Foram realizadas excursões mensais entre outubro de 2010 e maio de 2012 para coleta de material botânico seguindo o método de caminhamento livre (Filgueiras et al. 1994) e o material coletado foi processado conforme a metodologia usual em Taxonomia Vegetal. O material foi e incorporado ao acervo do Herbário da Universidade Federal de Goiás (UFG). A identificação dos táxons se baseou, principalmente, em Costa (2007), Lewis et al.
(2005), Queiroz (2009), Silva (1986), Vaz (2003) e também em coleções herborizadas (UB, IBGE, CEN, UFG; acrônimos segundo Thiers 2016). As descrições dos táxons estudados seguem baseadas nas literaturas previamente citadas, as quais serviram para identificá-los, e contemplaram as variações morfológicas dos indivíduos registrados para cada um deles. A terminologias para designação dos tipos de frutos seguiram Barroso et al. (1999).

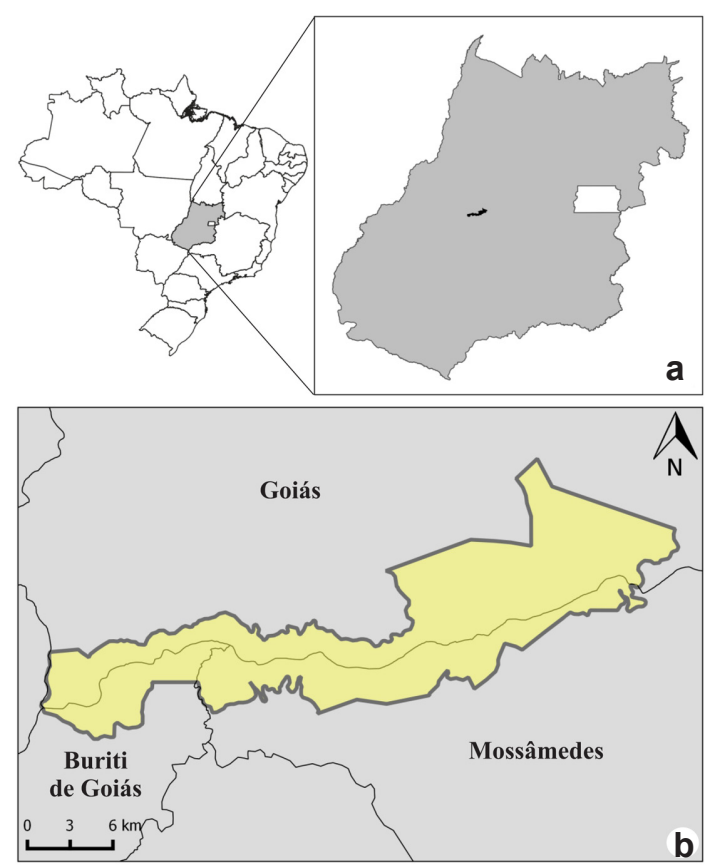

Figura 1 - a. mapa mostrando a localização do Parque Estadual da Serra Dourada (GO) em preto; b. área do PESD em amarelo, limites dos municípios em linhas finas.

Figure 1 - a. map showing the locality of Serra Dourada State Park (GO) in black; b. area of SDSP in yellow, limits of municipalities in thin lines.

\section{Resultados e Discussão}

$\mathrm{Na}$ área estudada foram encontradas 15 espécies, seis delas para o gênero Bauhinia ( $B$. brevipes Vogel, B. curvula Benth., B. gardneri Benth., B. mollis D. Dietr., B. rufa (Bong.) Steudel e B. ungulata var. cuiabensis Vaz), duas para Tachigali (T. aurea Tul.e T. vulgaris L.F. Gomes da Silva \& H.C. Lima), duas para Hymenaea (H. courbaril L. e H. stignocarpa var. pubescens Benth.), além de Apuleia leiocarpa (Vogel) J.F. Macbr, Copaifera langsdorffii Desf., Dimorphandra mollis Benth., Schnella outimouta (Aublet) Wunderlin e Peltogyne confertiflora (Mart. ex Hayne) Benth. 


\section{Chave dos gêneros estudados}

1. Folhas com pontuações translúcidas. subfamília Detarioideae

2. Folhas com mais de um par de folíolos; flores monoclamídeas 3. Copaifera

2'. Folhas com um par de folíolos; flores diclamídeas.

3. Legumes planos, deiscentes, monospérmicos 6. Peltogyne

3'. Legumes nucoides cilíndricos, indeiscentes e com mais de uma semente

4. Hymenaea

1'. Folhas sem pontuações translúcidas.

4. Folhas unifolioladas, bilobadas, raro bifolioladas, com venação palmatinérvia; hipanto presente, cálice gamossépalo. subfamília Cercidoideae

5. Lianas com gavinhas; hipanto campanulado...... 7. Schnella

5'. Subarbusto a arvoretas sem gavinhas; hipanto cilíndrico ...

2. Bauhinia

4'. Folhas bifolioladas ou multifolioladas, com venação peninérvia, cálice dialissépalo; hipanto ausente subfamília Caesalpinioideae (exceto clado Mimosoid)

6. Folhas bipinadas 4. Dimorphandra

6'. Folhas apenas pinadas.

7. Folhas imparipinadas; folíolos alternos; flores 3-meras

1. Apuleia

7'. Folhas paripinadas; folíolos opostos; flores 5-meras 8. Tachigali

\section{Apuleia Mart.}

Gênero sulamericano com duas ou três espécies (Queiroz 2009), facilmente reconhecido pelo caule com ritidoma amarelado, folhas imparipinadas com folíolos alternos e legumes samaróides e alados na margem superior. Neste estudo está representado por Apuleia leiocarpa.

\subsection{Apuleia leiocarpa (Vogel) J.F. Macbr; Contr.} Gray Herb. 59: 23. $1919 . \quad$ Fig. 2a

Árvore 7-8 m alt. Ramos glabrescentes, lenticelas evidentes. Estípulas 2-4 mm compr., ovais a oval-lanceoladas. Folhas imparipinadas, 7-9 folioladas, folíolos alternos, sem pontuações translúcidas; pecíolo 9-15 mm compr.; raque 4-7,5 cm compr.; folíolos 2,8-6 × 1,8-2,8 cm, alternos, elípticos a ovais, base obtusa, ápice acuminado, agudo ou obtuso, face adaxial esparso pubescente, face abaxial serícea. Dicásios 2-3 $\mathrm{cm}$ compr., congestos. Flores menores que 1 cm compr., 3-meras; pedicelo 5-7 $\mathrm{mm}$ compr., hipanto 1-1,5 mm compr., campanulado; sépalas $3-4 \times 1,2-2,5 \mathrm{~mm}$, oblongas a oblongo-obovais, reflexas, externamente tomentosas; pétalas $3-5$ $\times 1,5-2 \mathrm{~mm}$, oblongo-elípticas a espatuladas, brancas; estames 3(-4), 3-5 mm compr., anteras basifixas, deiscência poricida apical; ovário 2-3 mm compr., seríceo, curtamente estipitado, 1-4 ovulado, estilete espessado, estigma oblíquo. Legumes samaróides 4,8-6,2 × 2,4-2,8 cm, elípticos a obovais, alados na face superior, estipe 1-2 cm compr., seríceo-ferrugíneos.
Material examinado: Mossâmedes, PESD, Lado direito do Córrego do Piçarrão, 28.X.2011, fr., M.M. Dantas 26 (UFG).

Única dentre as demais espécies estudadas a possuir folhas imparipinadas, flores 3-meras e legumes samaróides, caracteres estes, diagnósticos para o seu reconhecimento. Ocorre do leste do Brasil até a Argentina e Paraguai (Queiroz 2009). Foi encontrada crescendo na borda de Floresta Estacional do Córrego do Piçarrão.

\section{Bauhinia L.}

Subarbustos a árvores, inermes ou aculeados, glabros a indumentados. Estípulas aculeiformes ou não. Folhas inteiras a bilobadas ou bifolioladas, pecioladas, sem pontuações translúcidas, venação palmada. Pseudorracemos terminais ou flores geminadas supra-axilares; botões tomentoso-ferrugíneos ou tomentosooliváceos; brácteas e bractéolas, caducas ou persistentes, foliáceas, nectaríferas. Flores 5-meras, zigomorfas, diclamídeas, pétalas brancas ou cremes, lineares a linear-lanceoladas, glabras a indumentadas; hipanto cilíndrico; cálice com lacínios, ondulados a retorcidos; estames 10 , isomorfos, livres ou basalmente unidos, anteras rimosas; ovário linear, estipitado, pluriovulado, estigma claviforme ou bilobado. Legumes elasticamente deiscentes, valvas coriáceas a lenhosas. Sementes numerosas de forma variadas, castanho-claro a escuros. 
Bauhinia ocorre nos trópicos e reúne cerca de 160 espécies (Lewis et al. 2005), 60 delas referidas para o Brasil(BFG 2015). Compartilha com o gênero Schnella as folhas bilobadas com venação palmatinérvia, porém difere deste último pelo hábito subarbustivo a arbóreo (vs. lianas em Schnella) nunca com gavinhas (vs. com gavinhas), inflorescência pseudorracemosa (vs. racemo) e cálice cilíndrico-tubuloso ( vs. campanulado). No PESD está representado por seis espécies, conforme a chave abaixo:

\section{Chave de identificação das espécies de Bauhinia ocorrentes no PESD}

1. Folhas bifolioladas

2.2. Bauhinia curvula

1'. Folhas unifolioladas.

2. Ramos aculeados; inflorescências supra-axilares

2.4. Bauhinia mollis

2'. Ramos inermes; inflorescências terminais.

3. Pecíolo 3-7 mm compr.; flores 3,5-4,5 cm compr.

2.1. Bauhinia brevipes

3'. Pecíolo 10-45 mm compr.; flores 5,5-10,5 cm compr.

4. Subarbustos glabros; hipanto seríceo internamente

2.3. Bauhinia gardneri

4'. Arbustos a arvoretas indumentados; hipanto glabro internamente.

5. Folhas com face abaxial esparsamente tomentosa, nervuras terciárias impressas.. 2.6. Bauhinia ungulata var. cuiabensis

5'. Folhas com face abaxial tomentoso-ferrugínea, nervuras terciárias proeminentes. 2.5. Bauhinia rufa

2.1. Bauhinia brevipes Vogel, Linnaea 13: 307. 1839.

Fig. 2b,c

Arbusto 1,6-3 m alt. Ramos vilosoferrugíneos, inermes. Folhas 3,5-7,5 × 1,8-3,2 $\mathrm{cm}$, unifolioladas, curtamente bilobadas, cartáceas a subcoriáceas, oval-oblongas raro elípticas ou lanceoladas, base cordada a subtruncada, face adaxial tomentosa, face abaxial viloso-ferrugínea, glandulosa; lobos agudos a obtusos, concrescidos em mais de $2 / 3$ de seu comprimento; pecíolo 3-7 mm compr.; estípulas 5-8 $\mathrm{mm}$ compr., linear-lanceoladas. Pseudorracemos $15-45 \mathrm{~cm}$ compr. terminais; brácteas 3-6 $\mathrm{mm}$ compr., oblongas, persistentes; botões $3,5-5 \mathrm{~cm}$ compr., subclavados, lisos a estriados. Flores 3,5-4,5 cm compr.; bractéolas $3-5 \mathrm{~mm}$ compr., linearlanceoladas, persistentes; hipanto 8-13 × 5-7 mm compr., internamente glabro; cálice $2-3$ fendido, lobos 2-3,5 cm compr.; pétalas $2-2,8 \times 0,2-0,4$ $\mathrm{cm}$, linear-lanceoladas; filetes $2-2,7 \mathrm{~cm}$ compr., coluna estaminal 1-2 mm compr., internamente indumentada; ovário 1-1,5 cm compr., tomentoso a viloso, estipe $2-2,5 \mathrm{~cm}$ compr., glabro. Legumes 11,5-15,5 × 1-1,2 cm, lineares, tomentosos.

Material examinado: Mossâmedes, PESD, entre o Córrego do Piçarrão e a sede do Parque, 1.VII.2011, f1., M.J. Silva 3691, 3696 (UFG); 30.IX.2011, fl. e fr., M.M. Dantas 14 (UFG); trilha que leva à base do morro da Asa Delta, 3.III.2012, fr., M.M. Dantas 122 (UFG).

Espécie reconhecida e distinta das demais congêneres pelo aspecto esguio e folhas curto- pecioladas (pecíolo até $7 \mathrm{~mm}$ compr.) com limbo curto bilobado. É citada para a Bolívia e Brasil (Centro-Oeste GO, MT e MS, Nordeste BA, PI, Norte TO e RO, e Sudeste SP), (Vaz \& Tozzi 2003). Coletada na Floresta Estacional do Córrego do Piçarrão e do morro da Asa Delta.

2.2. Bauhinia curvula Benth., Fl. bras. 15(2): 194 . 1870 .

Fig. $2 d$

Subarbusto a arbusto $0,8-2 \mathrm{~m}$ alt. Caule e ramos tomentosos, inermes. Folhas bifolioladas, folíolos 1,8-5,8 × 0,7-1,5 cm, oblongo-falcados, arredondados a obtusos, cartáceos, glabros na face adaxial e tomentoso-glandular na face abaxial; pecíolo 0,5-1,1 cm compr.; estípulas vestigiais; nectários extraflorais subulados. Pseudorracemos 6-18 cm compr., terminais; brácteas e bractéolas escamiformes, as primeiras nectaríferas; botões 2,5-3,5 cm compr., lineares, lisos. Flores 3,5-4,5 cm compr.; cálice 3-5-lobado, lobos 2,5-3,5 cm compr.; pétalas 20-25 × 1-2 mm, lineares; ovário 1-1,7 cm compr., glanduloso, estipe 1,6-2,1 cm compr., glanduloso; hipanto 8-10 $\times 6-8 \mathrm{~mm}$, cilíndrico, internamente esparso tomentoso na região distal; filetes $2-3,2 \mathrm{~cm}$ compr., coluna estaminal $3-5 \mathrm{~mm}$ compr., tomentosa internamente. Legumes 7,5-12 × 7-9 cm, lineares, glabros, esparsamente glanduloso.

Material examinado: Mossâmedes, PESD, próximo à cancela de acesso à sede do Parque, 25.III.2011, fl., M.J. Silva 3499 (UFG); 29.IV.2011, fl., M.J. Silva 3597 


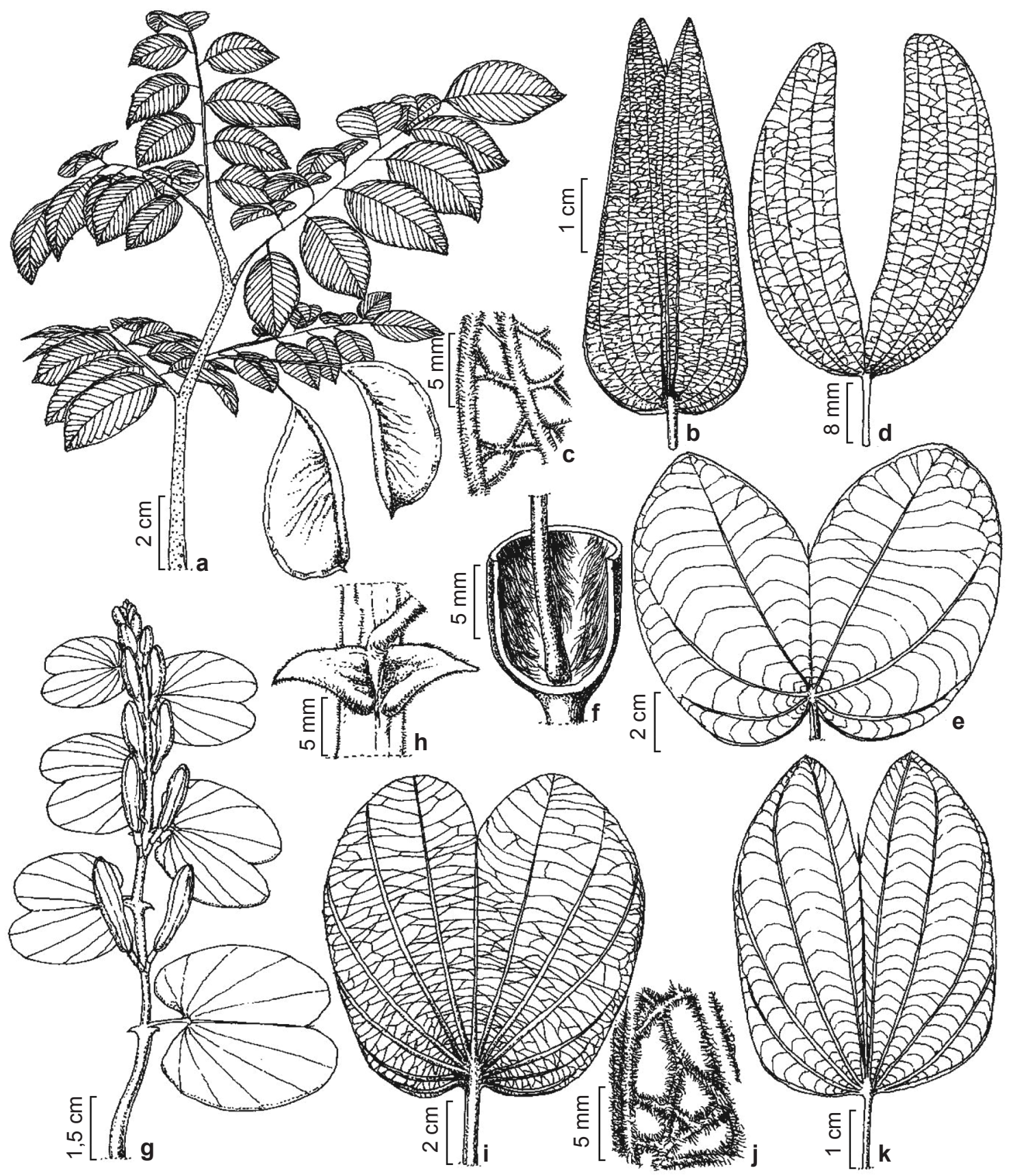

Figura 2 - a. Apuleia leiocarpa. b-c. Bauhinia brevipes - b. folha; c. detalhe da face abaxial da folha mostrando o indumento. d. B. curvula - folha. e-f. B. gardneri - e. folha; f. detalhe do indumento interno do hipanto. g-h. $B$. mollis - g. ramos fértil; h. acúleos. i-j. B. rufa - i. folha, j. detalhe da face abaxial da folha mostrando o indumento. k. B. ungulata - folha.

Figure 2 - a. Apuleia leiocarpa. b-c. Bauhinia brevipes - b. leaf; c. detail of the abaxial surface of the leaf showing the indumentum. $d$. B. curvula - leave. e-f. B. gardneri-e. leaf; f. detail of internal indumentum of hypanthium. g-h. B. mollis - g. fertile branch; h. hooklets. $\mathrm{i}-\mathrm{j}$. B. rufa - i. leaf, j. detail of the abaxial surface of the leaf showing the indumentum. k. B. ungulata - leaf. 
(UFG); imediações da porteira que dá acesso ao Areal, 27.V.2011, fl. e fr., M.J. Silva 3646 (UFG); próximo a afloramento rochoso antes da cancela que dá acesso ao Parque, 2.VII.2011, fr., M.J. Silva 3734 (UFG); 26.VIII.2011, fr., M.M. Dantas 9 (UFG).

Espécie reconhecida entre as demais pelas folhas bifolioladas. É endêmica do Brasil (DF, GO, MG, MT e PA), (Vaz \& Tozzi 2003). Neste estudo foi encontrada em Cerrado s.s. em distintas localidades.

2.3. Bauhinia gardneri Benth., Fl. bras.15(2): 186 . 1870 .

Fig. 2e,f

Subarbusto a arbusto 0,7-1,2 m alt.; ramos glabros. Folhas 8,5-14,5 × 11-18 cm, unifolioladas, bilobadas, obovais, ovais ou suborbiculares, base profundamente cordada a lobadas, glabras, nervuras proeminentes na face abaxial, coriáceas a subcoriáceas; lóbulos concrescidos em 3/4 ou em $2 / 3$ de seu comprimento, ápice arredondado a obtuso; pecíolo 1-3 cm compr.; estípulas 2-2,5 mm compr., oval-lanceoladas, caducas; nectários extraflorais não vistos. Pseudorracemos 30-45 cm compr. brácteas 1-2 mm compr., terminais; botões 6-9 cm compr., lineares, lisos ou estriados. Flores 8-10,5 cm compr; hipanto 10-15 × 5-7 $\mathrm{mm}$, cilíndrico, internamente seríceo; bractéolas diminutas; cálice 2-4-lobado, lobos 6,5-7,5 cm compr.; pétalas 25-35 × 1-1,5 mm, linearlanceoladas; filetes 4,5-6,5 cm compr., coluna estaminal 6-10 mm compr., externamente glabra, internamente serícea; ovário 15-20 mm compr., glanduloso, estipe 3,5-4,5 cm compr., glabro. Legumes 16-18 × 1,1-1,5 cm, lineares, glabros.

Material examinado: Mossâmedes, PESD, após o areal, 27.IX.2010, f1., A.M. Teles et. al 1032 (UFG); próximo a cancela de acesso a sede do Parque, 25.III.2011, fl., M.J. Silva 3494 (UFG).

Pelos ramos glabros, folhas com lobos suborbiculares e base profundamente cordada esta espécie diferencia-se das demais estudadas. Ocorre na Bolívia e no Brasil onde até então era citada apenas para o estado do Tocantins (Vaz 2003), sendo, portanto, primeiramente referida para Goiás neste estudo. Foi coletada em Cerrado s.S.

\subsection{Bauhinia mollis (Bong.) D. Dietr., Syn. Pl. 2:} 1475. 1840.

Fig. $2 \mathrm{~g}, \mathrm{~h}$

Subarbusto a arbusto 1,2-2 m alt. Ramos tomentoso-oliváceos, aculeados. Folhas 3,7-6,2 $\times$ 4,3-7,2 cm, unifolioladas, bilobadas, orbiculares a ovais-elípticos, base cordada a levemente truncada, face adaxial glabra, face abaxial vilosa, cartáceas; lóbulos concrescidos acima de $2 / 3$ de seu comprimento a quase unidos, ápice obtuso a arredondado; pecíolo 1-2 cm compr.; estípulas 5-8 mm compr., lineares, tardiamente caducas; nectários extraflorais ausentes. Inflorescência 2-flora, geminada, supra-axilar; brácteas 5-7 mm compr., linear-lanceoladas; botões $4-5,5 \mathrm{~cm}$ compr., clavados, lisos; bractéolas 5-7 mm compr., linear-lanceoladas. Flores 6-7,5 cm compr.; hipanto 10-13 $\times 5-7 \mathrm{~mm}$, tubuloso-ovoide, internamente glabro; cálice 2-3-lobados, lobos 3,5-4,5 cm compr., unidos no ápice até quase espatulado; pétalas 5,5-6 × 0,3-0,5 mm, linear-oblongas; filetes $4-5 \mathrm{~cm}$ compr.; coluna estaminal $5-7 \mathrm{~mm}$ compr., internamente glabra; ovário 1,5-2 cm compr., tomentoso, estipe 2,5-3,5 cm, glabrescente. Legumes 14-20 × 1,2-1,7 cm, linear-oblongos, tomentosos.

Material examinado: Mossâmedes, PESD, próximos aos Córregos Canfudó e Piçarrão, 14.XII.1994, fl. e fr., J.A. Rizzo et al. 12196 (UFG); na base para a sede do Parque, 12.X.1996, fl., A.S.F. Vaz 1060 (UFG); 7.XI.2010, fl., M.J. Silva 3217 (UFG); próximo a cancela que dá acesso ao Córrego do Piçarrão, 2.III.2012, fl. e fr., M.M. Dantas 102 (UFG).

Dentre as espécies estudadas $B$. mollis é a única que possui acúleos, inflorescências supra-axilares com flores geminadas e cálice subespatáceo. Distribui-se na Bolívia, Brasil (GO, MG, MT, MS, TO) e Paraguai (Vaz \& Tozzi 2003). Coletada na borda da Floresta Estacional.

2.5. Bauhinia rufa (Bong.) Steudel, nom. Bot. ed.2, 1:192. 1840.

Fig. 2i,j

Arbustos a arvoretas 1-5 malt. Ramos inermes, tomentoso-ferrugíneos. Folhas unifolioladas 6-11 $\times 5-11 \mathrm{~cm}$, bilobadas, ovais a elípticas, base cordada a subtruncada, face adaxial glabra, face abaxial tomentoso-ferrugínea, nervuras terciárias proeminentes na face abaxial, coriáceos; lóbulos concrescidos em $2 / 3$ a $3 / 4$ de seu comprimento, ápice agudo a obtuso ou arredondado; pecíolo 1,5-4,5 cm compr.; estípulas 5-7 cm compr., linearlanceoladas, persistentes; nectários extraflorais 2-3 mm compr., subulados. Pseudorracemos 10-25 cm compr., terminais; brácteas 3-6 mm compr., lanceoladas a triangulares; botões 6-9 cm compr., clavados, estriados; bractéolas 3-5 $\mathrm{mm}$ compr., linear-lanceoladas. Flores $7-10 \mathrm{~cm}$ compr., hipanto $1,8-2,5 \times 0,8-1 \mathrm{~cm}$ compr., cilíndrico, internamente glabro; cálice 4-5-lobado, lobos 5,5-7 cm compr.; pétalas 4-5,5 $\times 0,1-0,25 \mathrm{~cm}$, lineares; filetes 3,5$5,5 \mathrm{~cm}$ compr., coluna estaminal $1-2 \mathrm{~mm}$ compr., glabra; ovário 1,6-2,1 cm compr., tomentoso, estipe 
3-4 cm compr., tomentoso. Legumes $12-17 \times 1,5-2$ $\mathrm{cm}$, oblongos, curto-tomentosos.

Material examinado: Mossâmedes, PESD, a $3 \mathrm{~km}$ do trevo da cidade de Mossâmedes para Goiás, 17.III.1994, fl., J.A. Rizzo et al. 11063 (UFG); imediações da cancela que dá acesso a sede do parque, 28.I.2011, fl., M.J. Silva 3329 (UFG); próximo a cancela que dá acesso ao areal, 27.V.2011, fl. e fr., M.J. Silva 3645, 3647 (UFG); estrada para o mirante, 25.III.2011, fl. e fr., M.J. Silva 3480 (UFG); imediações do areal, 29.X.2011, fr., M.M. Dantas 30 (UFG).

Pode ser reconhecida pelos ramos, pecíolo, raque da inflorescência e face abaxial das folhas tomentoso-ferrugíneos, folhas curtamente bilobadas e coriáceas com nervuras secundárias e terciárias proeminentes na face abaxial. Endêmica do Brasil (DF, GO e MG) onde cresce em Campos Rupestre, Cerrado s.s. e Florestas Estacionais (Vaz \& Tozzi 2003), ambiente em que também a coletamos no PESD.

\subsection{Bauhinia ungulata var. cuiabensis Vaz,} Rodriguésia 54: 125. $2003 . \quad$ Fig. 2k

Arbusto a arvoreta 2,3-4 m alt. Ramos inermes curto-tomentoso. Folhas unifolioladas $4-7 \times 3,5-6 \mathrm{~cm}$, bilobadas, ovais ou oblongas, base subcordada a truncada, face adaxial glabra, face abaxial esparsamente curto-tomentosa, cartáceos a subcoriáceos; nervuras secundárias pouco proeminentes e terciarias impressas; lóbulos concrescidos em $2 / 3$ de seu comprimento, ápice agudo a obtuso ou raro arredondado; pecíolo $1-3,5 \mathrm{~cm}$ compr.; estípulas $7-15 \times 3-5 \mathrm{~mm}$, ovallanceoladas ou obovais, persistentes; nectários extra-florais não vistos. Pseudorracemos 15-25 cm compr., terminais, brácteas $5-10 \mathrm{~cm}$ compr., ovais a oblongo-ovais, persistentes; botões 4-5,5 cm compr., subclavados, estriados. Flores 5,5-8,5 cm compr., bractéolas 4-8 $\mathrm{mm}$ compr., oval-lanceoladas; hipanto $10-15 \times 5-7 \mathrm{~mm}$, internamente glabro; cálice 3-5-lobado, lobos 3,2-3,7 cm compr.; pétalas $3-3,4 \times 0,1-0,3 \mathrm{~cm}$, linear-lanceoladas; filetes $3,5-4 \mathrm{~cm}$ compr.; coluna estaminal 1-3 mm compr., glabra; ovário 1,5-2,2 cm compr., tomentoso, estipe $3-3,5 \mathrm{~cm}$ compr., glabro. Legumes $12-18 \times 0,9-1,1 \mathrm{~cm}$, linearoblongos, tomentosos.

Material examinado: Borda da represa que abastece a cidade de Mossâmendes, 12.X.1996, fr., A.S.F. Vaz 1059 (UFG); estrada entre o Córrego do Piçarrão e a sede, 1.VII.2011, fl. e fr., M.J. Silva 3704, 3708, 3709 (UFG); próximo a última cancela que dá acesso ao Córrego do Piçarrão, 2.III.2012, fl. e fr., M.M. Dantas 101 (UFG).
Espécie que juntamente com o hábito de arbustivo a arbóreo torna-se distinta das demais pelas folhas com nervuras terciarias impressas na face abaxial e brácteas persistentes na inflorescência. Ocorre no Paraguai e Brasil (BA, DF, GO, MT, MS, MG, RJ, SP e TO) crescendo em Cerrado s. lat. (Vaz \& Tozzi 2003). Coletada na Mata de Galeria do Córrego do Piçarrão.

\section{Copaifera L.}

Gênero pantropical com 38 espécies, 33 das quais americanas. No Brasil é representado por 26 espécies, 22 delas endêmicas (Costa 2007). Caracteriza-se pelas folhas paripinadas com pontuações translúcidas, flores monoclamídeas e sementes ariladas.

3.1. Copaifera langsdorffii Desf. Mem. Mus. Hist. Nat. 7: 377. 1821.

Fig. 3a-d

Árvores 3-12 m alt., inermes. Folhas paripinadas, 8-10-folioladas, folíolos opostos a alternos com pontuações translúcidas; estípulas decíduas; pecíolo 5-10 mm compr., raque 3,5-5 cm compr., ambos vilosos; nectários ausentes; folíolos 1,5-3,8 × 0,9-1,5 cm, oblongos a elípticos, base assimétrica ou arredondada, ápice obtuso a retuso, seríceos em ambas as faces, margem ciliada, venação reticulada. Panículas 5-9 cm compr., axilares; brácteas caducas. Flores tetrâmeras, monoclamídeas, actinomorfas; sépalas $4-5 \times$ 2-3 mm, oblongas a ovais, agudas, seríceas; estames 10, livres, glabros, anteras dorsifixas, rimosas; ovário 1,8-2 × 1,5-1,8 mm, suborbicular, margem hirsuta, 2-ovulado, estilete curvo, estigma lobado. Legume 1,5-3 × 1,5-2,3 cm, suborbicular, deiscente, valvas lenhosas á coriáceas, glabras, marrons a avermelhadas, estípite $2-3 \mathrm{~mm}$ compr. Semente 1, 10-15 × 6-10 mm, elipsoide, negras, arilo alaranjado.

Material examinado: Mossâmedes, PESD, divisa dos municípios de Mossâmedes ao sul e Goiás ao norte, 1.VI.1969, fr., J.A. Rizzo 4282 (UFG); 6.XII.1969, fl., J.A. Rizzo 4579 (UFG); região após ao Areal, 27.V.2011, fl. e fr., M.J. Silva 3673 (UFG).

Diferencia-se facilmente dos demais táxons estudados pelas folhas com 3-4(-6) pares de folíolos com pontuações translúcidas e flores monoclamídeas. Distribui-se das Guianas até o Paraguai, sendo no Brasil, registrada para a Bahia, Goiás, Mato Grosso do Sul, Minas Gerais e São Paulo associada a Florestas Decíduas e cerradão (Costa 2007), ambiente em que aqui também foi coletada. 


\section{Dimorphandra Schott.}

Gênero sulamericano (Bolívia, Brasil, Colômbia, Guianas, Paraguai, Peru e Venezuela) (Lewis et al., 2005) reconhecido pelas folhas bicompostas e androceu com 5 estames epipétalos alternados a 5 estaminódios. No Brasil está representado por 26 espécies (Silva 1986), uma das quais, Dimorphandra mollis encontrada neste estudo.

4.1. Dimorphandra mollis Benth., J. Bot. (Hooker) 2(10): 102. 1840.

Fig. 3e-g

Árvores 2,5-10 m alt., ramos tomentosoferrugíneos; estípulas caducas. Folhas bipinadas, pinas 9-11 pares, opostas a subopostas; pecíolo 4-7 cm compr., tomentoso-ferrugíneo, nectário ausente; raque 19,5-33,5 cm compr., raque da pina 10-17,5 cm compr., ambas tomentosas; folíolos $0,7-1,7 \times 0,4-0,8 \mathrm{~cm},(13-) 17-24$ pares por pina, alternos a subopostos, oblongos, raro elípticos, base obtusa a truncada, ápice obtuso, tomentosos em ambas as faces, margem revoluta, sem pontuações translúcidas, venação broquidódroma. Panículas de espigas até $15 \mathrm{~cm}$ compr., terminais; brácteas e bractéolas caducas. Flores actinomorfas, cálice 5-laciniado, sépalas esparso-seríceas; pétalas 2-3 $\times 1,5-2 \mathrm{~cm}$, obovoides, reflexas; estames 2,8-3,5 cm compr., 5 epipétalos alternos a 5 estaminódios, anteras rimosas, dorsifixas, isomórficas; ovário 2-3 $\mathrm{mm}$ compr., glabro, curto-estipitado, multiovulado, estigma inconspícuo. Legumes nucóides 6-10 × 2,5$3,2 \mathrm{~cm}$, oblongos, curto-estipitados, compressos, glabros, indeiscentes. Sementes não vistas.

Material examinado: Mossâmedes, PESD, a $3 \mathrm{~km}$ do trevo de Mossâmedes para a cidade de Goiás, à esquerda da rodovia, 17.XI.1994, fl., J.A. Rizzo et al. 11987 (UFG); próximo à estrada que segue para o Areal, 27.X.1997, fl., V.L. Gomes-Klein et al. 3363 (UFG); próximo à Mata Seca em Cerradão, 28.X.2011, fl., M.M. Dantas
25 (UFG); trilha para a base do morro da Asa Delta, 3.III.2012, fr., M.M. Dantas 124 (UFG).

Espécie reconhecida por ser a única entre as estudadas a apresentar folhas bicompostas e inflorescência do tipo panícula-espiciforme. Ocorre no Brasil (Distrito Federal, Goiás, Mato Grosso, Minas Gerais e São Paulo), na Bolívia e no Paraguai (Silva 1986). Na área estudada foi coletada em Cerrado s.s.

\section{Hymenaea L.}

Árvores ou arbustos, resinosos. Folhas bifolioladas com pontuações translúcidas, estípulas caducas. Panículas curtas corimbiformes; botões ovoides ou claviformes. Flores actinomorfas, curto pediceladas, hipanto campanulado; brácteas e bractéolas caducas; sépalas 4, carnosas, fortemente imbricadas; pétalas 5, subdesiguais, brancas ou cremes; estames 10, filetes longos, anteras rimosas; ovário compresso, estipitado, glabro, multiovulado. Frutos legumes nucóides oblongos, cilíndricos, rugosos ou lisos. Sementes envolvidas pelo endocarpo.

Gênero anfi-atlântico com 14 espécies, 13 delas neotropicais, e uma africana (Lee \& Langenheim 1975). As folhas bifolioladas com base assimétrica e limbo com pontuações translúcidas, associados aos legumes nucóidess cilíndricos identificam Hymenaea. Assemelha-se ao gênero Peltogyne com o qual compartilha as folhas bifolioladas com base assimétrica e limbo com pontuações translúcidas, o tipo de inflorescência e as flores. Mas, difere principalmente pela forma e consistência dos legumess os quais em Hymenaea são oblongos (vs. subtriangulares ou suborbiculares em Peltogyne), cilíndricos (vs. compresso), indeiscentes ( $v s$. deiscente) e com mais de uma semente (vs. uniseminados). No PESD está representado por duas espécies.

\section{Chave de identificação das espécies de Hymenaea ocorrentes no PESD}

1. Folíolos oblongo-elípticos ou elíptico-falcados, ápice agudo ou acuminado, glabros em ambas as faces 5.1. Hymenaea courbaril

1'. Folíolos oblongos-obovais ou oblongo-elípticos, ligeiramente falcados, ápice obtuso a arredondado, tomentosos na face abaxial 5.2. Hymenaea stigonocarpa var. pubescens

5.1. Hymenaea courbaril L. Sp. Pl. 2: 1192. 1753.

Fig. 3h,i

Árvores 8-25 m alt., ramos glabros; pecíolo 1-2 cm compr., glabro; folíolos 5-10,5 × 1,7-3,7 $\mathrm{cm}$, oblongo-elípticos ou elíptico-falcados, ápice agudo ou acuminado, base assimétrica com um dos lados arredondado ou cordado, glabros em ambas as faces, nervura principal excêntrica, venação broquidódroma. Panículas 5-8 cm compr., terminais; botões florais $1-2,5 \times 0,5-1,1 \mathrm{~cm}$, clavados; hipanto 


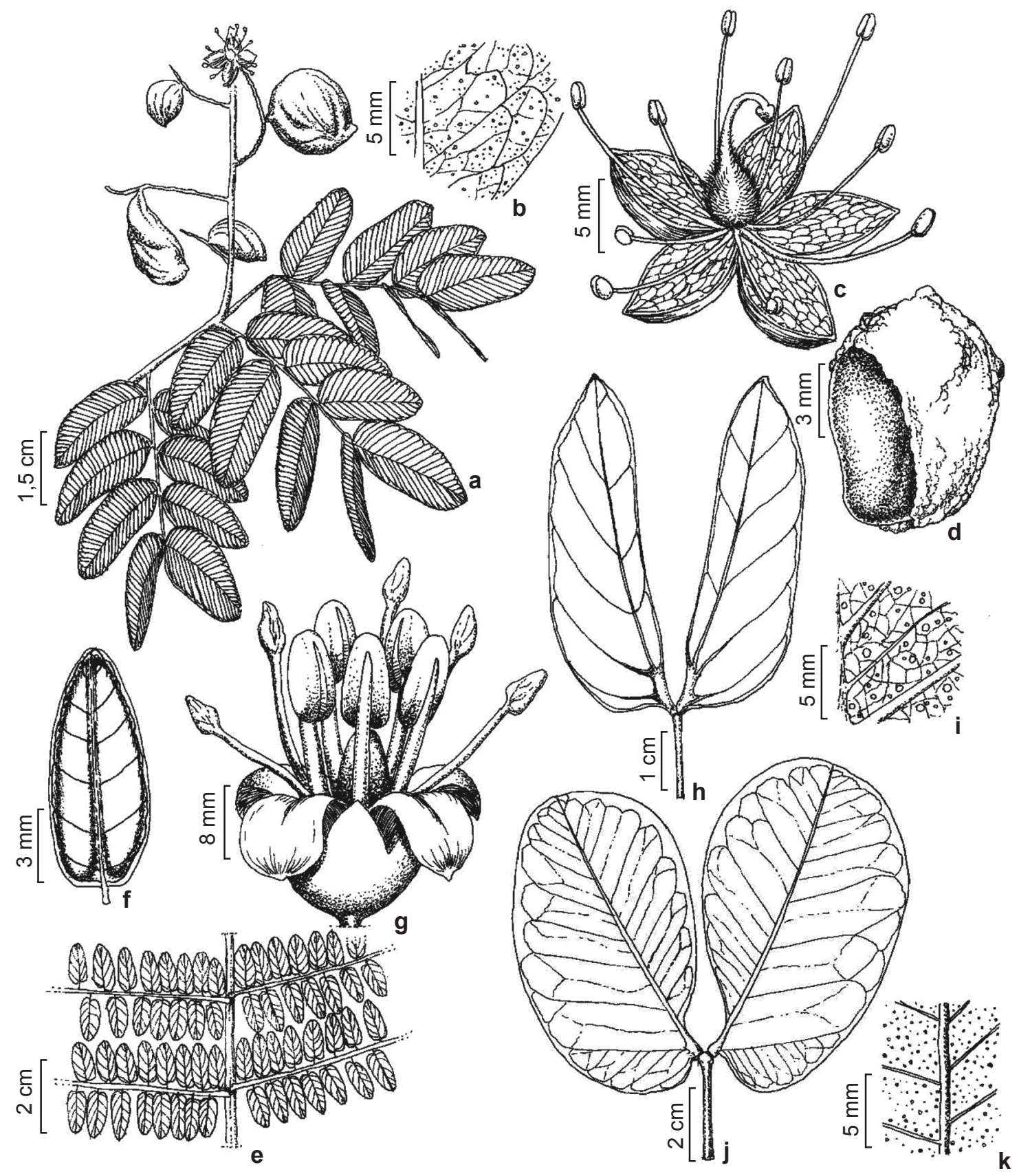

Figura 3 - a-d. Copaifera langsdorfii - a. ramo fértil; b. detalhe do folíolo mostrando as pontuações translúcidas; c. flor; d. semente. e-g. Dimorphandra mollis - e. folha; f. folíolo; g. flor. h,i. Hymenea courbaril - h. folha; i. detalhe do folíolo mostrando as pontuações translúcidas. j,k. H. stignocarpa - j. folha; k. detalhe do folíolo mostrando as pontuações translúcidas.

Figure 3 - a-d. Copaifera langsdorfii - a. fertile branch; b. detail of the leaflet showing the translucent punctuations; c. flower; d. seed. e-g. Dimorphandra mollis - e. leaf; f. leaflet; g. flower. h,i. Hymenea courbaril - h. leaf; i. detail of leaflet showing the translucent punctuations. j,k. H. stignocarpa - j. leaf; k. detail of leaflet showing Translucent Punctuations. 
4-6 mm compr.; sépalas 1,5-2 × 1,3-2 cm, ovaloblongas, seríceas ou tomentosas, verruculosas externamente; pétalas $1,4-2,3 \times 0,8-1,5 \mathrm{~cm}$, elíptico-oblongas; estames 1,4-2 cm compr.; ovário 6-8 $\mathrm{mm}$ compr., estipe 3-5 $\mathrm{mm}$ compr. Legumes nucóides 9-16 × 4-6 cm. Sementes não vistas.

Material selecionado examinado: Mossâmedes, PESD, estrada de acesso a sede acima do Córrego do Piçarrão, 26.VIII.2011, fr., M.J. Silva 3756 (UFG).

Os folíolos glabros, cartáceos, lanceolados a oblongo-falcados com ápice agudo a acuminado são caracteres que a diferencia de $H$. stigonocarpa var. pubescens cujos folíolos são indumentados, coriáceos e oblongos com ápices arredondados. Distribuída desde o sul do México, incluindo Antilhas, até o sudeste do Brasil (Lee \& Langenheim 1975). Coletada próximo a Floresta Estacional acima do Córrego do Piçarrão.

\subsection{Hymenaea stigonocarpa var. pubescens} Benth., Fl. bras. 15(2): 236. $1870 . \quad$ Fig. 3j,k Árvores 2,5-6 m alt., ramos glabros a esparsamente tomentosos; pecíolo 1,8-4 cm compr., tomentoso; folíolos 9-15 × 5-8 $\mathrm{cm}$, oblongos-obovais ou oblongo-elípticos, ligeiramente falcados, ápice obtuso a arredondado, base assimétrica com um dos lados arredondado ou cordado, face adaxial glabrescente a tomentosa, face abaxial tomentosa, principalmente sobre as nervuras, venação broquidódroma. Panículas $7-15 \mathrm{~cm}$ compr., terminais; botões $2-3 \times 1,2-1,5$ $\mathrm{cm}$, globosos; sépalas 1,4-2,2 × 1,4-2 cm, ovaloblongas, seríceas a tomentosas; pétalas 1,7-2,3 $\times 0,8-1,5 \mathrm{~cm}$, elípticas; estames $1,5-2,5 \mathrm{~cm}$ compr.; ovário 5-8 $\mathrm{mm}$ compr., estipe $3-5 \mathrm{~mm}$ compr. Legumes nucóides 8,5-11 × 2,3-4 cm. Sementes não vistas.

Material examinado: Mossâmedes, PESD, divisa dos municípios de Mossâmedes ao Sul e Goiás ao Norte, 4.V.1969, fl. e fr., J.A. Rizzo 4221 (UFG); 1.II.1970, fl., J.A. Rizzo 4705 (UFG); nas proximidades dos Córregos Cafundó e Piçarrão, 17.II.1994, fl., J.A. Rizzo et al. 10964, 10995 (UFG); Floresta Estacional na base do morro da Asa Delta, 16 $6^{\circ}$ '17, $8^{\prime \prime}$, 50¹0’35,9”'W, 775 m n.s.m., 3.III.2012, fl., M.M. Dantas 134 (UFG).

As relações morfológicas com $H$. courbaril foram discutidas nos comentários desta última. Hymenaea stigonocarpa var. pubescens é muito frequente no Cerrado s.l. das regiões CentroOeste (DF, GO e MT), Nordeste (BA, CE e MA), Norte (PA) e Sudeste (MG e SP) do Brasil. No PESD cresce em Cerrado s.s.

\section{Peltogyne Vogel.}

Gênero com cerca de 25 espécies distribuídas desde o México até o sudeste do Brasil (Lewis et al. 2005). Caracteriza-se pelas folhas bifolioladas com pontuações translúcidas, flores diclamídeas e legumes com uma única semente. As semelhanças morfológicas com Hymenaea foram abordadas nos comentários deste último.

6.1. Peltogyne confertiflora (Mart. ex Hayne) Benth. Fl. bras. 15(2): 232. $1870 . \quad$ Fig. 4a-c Árvore 2-6 m alt., ramos glabros; estípulas caducas; pecíolo de 1,8-2,6 cm compr. Folhas bifolioladas; folíolos $6,5-13,5 \times 3,5-6,6 \mathrm{~cm}$, oblongos a oblongo-elípticos, base assimétrica, ápice agudo ou arredondado, margem inteira, cartáceos, com pontuações translúcidas, venação broquidódroma, pontuações translúcidas por todo o limbo. Panículas 7-10 cm compr., terminais, congestas; brácteas caducas; bractéolas 5-6 $\times$ 3-30 mm, ovais ou orbiculares, externamente tomentosas, côncavas, ciliadas; botões 9-17 $\times$ 5-7 mm, subclaviformes, tomentosos; hipanto 13-16 × 4-6 mm, campanulado, tomentoso; sépalas 4, 9-13 × 6-9 mm, oblongo-elípticas a orbiculares, imbricadas, tomentosas em ambas as faces; pétalas $5,7-12 \times 3,5-5 \mathrm{~mm}$, obovais, glabras; estames 10, 2-2,5 cm compr., glabros; anteras oblongas, rimosas, dorsifixas; ovário 3-5 $\times 2,5-3,5 \mathrm{~mm}$, oboval, glabro; estípite 3-6 mm compr., viloso; estilete 1,5-2,5 cm compr., glabro, estigma capitado. Legume 4-5,5 × 2,3-4,3 cm, subtriangular ou suborbicular, lenhoso, plano, deiscente, castanho-avermelhado. Semente 1, 1,8-2 × 1-1,3 mm, oboval a oblongo-orbicular, castanho-escura.

Material Examinado: Mossâmedes, PESD, cabeceira do Rio Índio Grande, 13.I.1994, fl., J.A. Rizzo et al. 10913 (UFG); 17.II.1994, fl. e fr., J.A. Rizzo et al. 11006 (UFG); 13.V.1994, fr., J.A. Rizzo et al. 11336 (UFG); a 3 km do trevo para Mossâmedes, 12.V.1994, fr., J.A. Rizzo et al. 11311 (UFG).

Pode ser reconhecida pelos caracteres genéricos citados acima. Ocorre em todas as regiões do Brasil, exceto a região Sul. Foi coletada em Floresta Estacional.

\section{Schnella Raddi.}

Táxon neotropical com cerca de 47 espécies (Trethowan et al. 2015). As espécies são lianas com gavinhas com inflorescências racemosas e flores com hipanto campanulado. As relações morfológicas com Bauhinia são discutidas nos comentários desta última. 
7.1. Schnella outimouta (Aublet) Wunderlin, Phytoneuron 49: 4. $2010 . \quad$ Fig. 4d-f

Lianas. Gavinhas circinadas, persistentes. Ramos jovens, pecíolo, face abaxial das folhas, pedúnculo, raque, face externa das brácteas e bractéolas tomentoso- ferrugíneos; estípulas 5-10 × 3-7 mm, reniformes; pecíolo 1,5-3,5 cm compr. Folhas $4-9,5 \times 3,5-8,5 \mathrm{~cm}$, bilobadas, ovais, cartáceas, sem pontuações translúcidas, venação palmatinérvia, lobos concrescidos até a metade da lâmina foliar 2,2-5,5 cm, acuminados, divergentes, face adaxial glabra. Racemos 6-11 $\mathrm{cm}$ compr., axilares ou terminais, congestos; brácteas $6-7 \times 3-4 \mathrm{~mm}$, elípticas; bractéolas $6-6,5 \times 2-2,5 \mathrm{~mm}$, oblanceoladas; botões $7-8 \times$ 3-3,5 mm, ovoides, costados; hipanto 6-9 $\times 5-7$ $\mathrm{mm}$, campanulado, lacínios 3,5-5 × 1,5-2,5 mm, oblongas; pétalas 5, 9-14 × 4-7 mm, obovais, brancas; estames 10, férteis; ovário 4-5 × 1,5-2 $\mathrm{mm}$, séssil, viloso-ferrugineo, 4-5-ovulado. Legumes $6-8 \times 1,8-2,3 \mathrm{~cm}$ compr., oblongos, marrons, elasticamente deiscentes. Sementes não vistas.

Material examinado: Mossâmedes, PESD, 12.X.1996, fl. e fr., A.S.F. $\operatorname{Vaz} 1054$ (UFG).
Material examinado adicional: BRASIL. GOIÁS: Estrada Itaberaí-Itaporanga, município de Goiás Velho, 13.X.1996, fr., A.S.F. Vaz 1065 (UFG).

Espécie reconhecida e diferenciada das demais estudadas por ser a única com hábito lianescente e com gavinhas. Possui distribuição neotropical, sendo no Brasil encontrada nas regiões Sudeste, Centro-Oeste e Norte (Trethowan et al. 2015).

\section{Tachigali Aubl.}

Árvores. Folhas paripinadas, alternas e com folíolos opostos; sem pontuações translúcidas, multifolioladas, estípulas decíduas ou não. Panícula terminal. Flores 5-meras, actinomorfas, sésseis a pediceladas; cálice dialissépalo sépalas imbricadas; pétalas amarelas; estames 10, filetes espessados na base, anteras rimosas; ovário estipitado, 3-10 ovulado; hipanto curto. Criptossâmara plana. Semente 1, plana.

Gênero neotropical com cerca de 70 espécies principalmente amazônicas (Lewis et al. 2005). Inclui árvores com folhas paripinadas e sem nectários, flores actinomorfas com anteras rimosas e criptossâmaras.

\section{Chave de identificação das espécies de Tachigali ocorrentes no PESD}

1. Folíolos com ápice agudo ou curto acuminado; pétalas oblongas a elípticas.........8.1. Tachigali aurea

1'. Folíolos com ápice aristado; pétalas linear-oblanceoladas 8.2. Tachigali vulgaris

8.1. Tachigali aurea Tul., Arch. Mus. Hist. Nat. 4: 169. 1844.

Fig. 4g-i

Árvores 4-10 m alt. Ramos, pecíolo, raque, pedicelo, face externa das sépalas e eixos da inflorescência tomentosos; pecíolo $4-5,5 \mathrm{~cm}$ compr.; estípulas caducas; raque 6-23 cm compr. Folíolos 4-12 × 2,5-6 cm, ovais, oval-lanceolados, raro lanceolados, base oblíqua, ápice agudo ou curto acuminado, tomentelos em ambas as faces, ciliados; venação broquidódroma. Panículas 20 $35 \mathrm{~cm}$ compr., terminais; brácteas $2-3 \times 0,2-0,4$ $\mathrm{mm}$, lanceoladas, persistentes; botões $1,8-2,5 \times$ 1,6-2,5 mm, globosos, tomentelo; pedicelo 1,5-2 $\mathrm{mm}$; hipanto 1,5-2 $\mathrm{mm}$ compr., cupuliforme; sépalas $2,5-3,2 \times 2-2,7 \mathrm{~mm}$, orbiculares; pétalas $4-5 \times 2-2,5 \mathrm{~mm}$, oblongas a elípticas; filetes 5-7 $\mathrm{mm}$ compr., hirsuto-ferrugíneo na base; ovário 2-2,5 mm compr., estipe 1-1,5 mm compr., ambos hirsuto-ferrugíneos. Criptossâmaras 4-5,5 × 2-2,7 $\mathrm{cm}$, oblongo-elípticos ou elípticos. Sementes $3-3,5 \times 1,4-1,7 \mathrm{~cm}$, oblongas a oblongo-elípticas.
Material examinado: Mossâmedes, PESD, próximo aos Córregos Cafundó e Piçarrão, 14.XII.1994, fl., J.A. Rizzo et al. 12201 (UFG).

Diferencia-se de T. vulgaris pelos folíolos com ápice agudo ( $v s$. folíolos com ápice aristado) e pelas flores com pétalas oblongas a elípticas (vs. pétalas linear-oblanceoladas). Distribuí-se nos estados da Bahia, Distrito Federal, Goiás, Mato Grosso, Mato Grosso do Sul, Minas Gerais, Tocantins e São Paulo. Foi coletada próximo aos Córregos Cafundó e Piçarrão em Floresta Estacional.

8.2. Tachigali vulgaris L.F. Gomes da Silva \& H.C. Lima, Rodriguésia 58(2): 400. 2007.

Fig. $4 \mathrm{j}-1$

Árvores 8-20 m alt. Ramos, pecíolo e raque vilosos; pecíolo 3-6,5 cm compr.; estípulas caducas; raque 7-21,5 cm compr. Folíolos $6,5-12,5 \times 2,3-5,5 \mathrm{~cm}$, oblongos, oblongo-ovais ou raro lanceolados, base oblíqua, ápice aristado, 


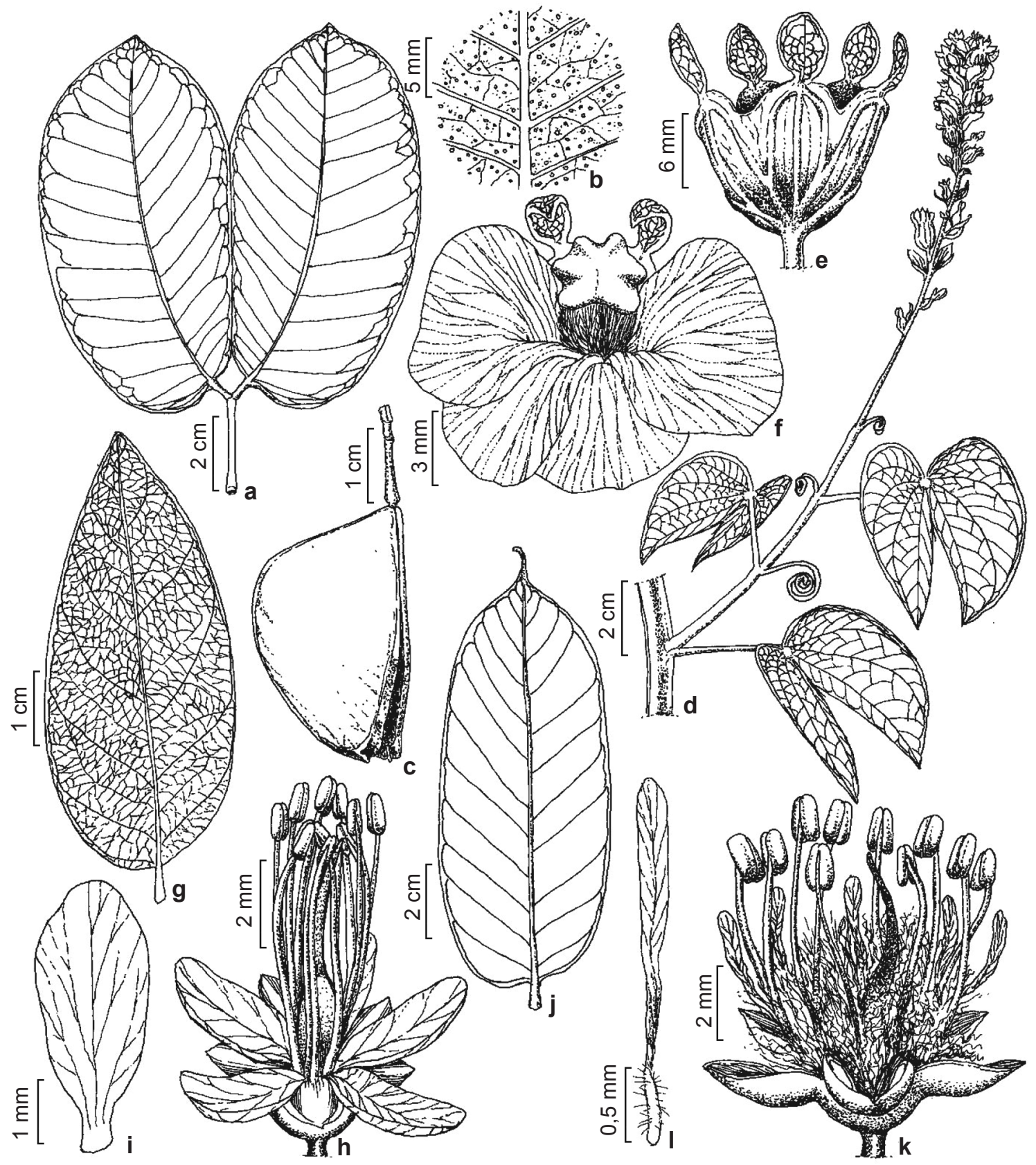

Figura 4 - a-c. Peltogyne confertiflora - a. folha; b. detalhe do folíolo mostrando as pontuações translúcidas; c. legume. d-f. Schnella outimouta - d. ramo fértil; e. cálice; f. pétalas. g-i. Tachigali aurea-g. folíolo; h. flor; i. pétala. j-1. T. vulgaris - j. folíolo; k. flor; 1. pétala.

Figure 4 - a-c. Peltogyne confertiflora - a. leaf; b. detail of the leaflet showing the translucent punctuations; c. fruit. d-f. Schnella outimouta - d. fertile branch; e. calyx; f. petals. g-i. Tachigali aurea - g. leaflets; h. flower; i. petal. j-1. T. vulgaris - j. leaflet; k. flower; 1. petal. 
face adaxial serícea a pilosa, face abaxial vilosa, discolores, margem inteira, ciliada, venação broquidódroma. Panículas 14-38 cm compr., axilares; brácteas caducas; botões florais 3-4 $\times$ 2,5-3,5 mm, globosos, seríceos; pedicelo 1,5-2 $\mathrm{mm}$, tomentoso; hipanto $1,2-2 \mathrm{~mm}$ compr., cupuliforme; sépalas 2,5-3 × 2,2-2,5 mm, ovais, elípticas ou orbiculares, externamente tomentosas; pétalas $3-4,5 \times 0,15-0,25 \mathrm{~mm}$, linear-oblanceoladas; filetes $4-6 \mathrm{~mm}$ compr., base hirsuto-ferrugínea; ovário $2-3 \mathrm{~mm}$ compr., hirsuto-ferrugíneo, estipe 0,8-1,4 $\mathrm{mm}$ compr., hirsuto ferrugíneo. Frutos não vistos. Sementes não vistas.

Material examinado selecionado: Mossâmedes, PESD, proximidades dos Córregos Cafundó e Piçarrão, 19.XII.1994, fl., J.A. Rizzo et al. 11561 (UFG).

As semelhanças morfológicas com T. aurea são discutidas nos comentários desta última. Espécie brasileira, com registro para a região amazônica, Bahia, Goiás, Maranhão, Mato Grosso, Mato Grosso do Sul, Minas Gerais, Piauí, São Paulo e Tocantins (BFG 2015). Foi coletada nas proximidades dos Córregos Cafundó e Piçarrão em Floresta Estacional.

\section{Agradecimentos}

Ao professor Aristônio Magalhães Teles, o apoio para a realização da pesquisa via Projeto "Levantamento Florístico do Parque Estadual da Serra Dourada"; à Universidade Federal de Goiás (UFG), o apoio logístico; ao CNPq, a bolsa de Iniciação Científica concedida ao primeiro autor; e ao desenhista Cristiano Gualberto, as ilustrações.

\section{Referências}

Barroso GM, Morin MP, Peixoto AL \& Ichaso CLF (1999) Frutos e sementes - morfologia aplicada à sistemática de dicotiledôneas. UFV, Viçosa. $443 p$.

Bentham G (1860) Leguminosae II e III. Swartizieae, Caesalpinieae, Mimosae. In: Martius CFP von. (ed.) Flora brasiliensis. Monachii, Lipsiae. Vol. 15, pars 2, 138 tab. pp. 1-504.

BFG - The Brazil Flora Group (2015) Growing knowledge: an overview of seed plant diversity in Brazil. Rodriguésia 66: 1085-1113.

Cochrane TT, Sanchez LG, Azevedo LG, Porras JA \& Garver CL (1985) Land in Tropical America. Vol. 3. CIAT/EMBRAPA-CPAC, Cali. 147p.

Costa JAS (2007) Estudos taxonômicos, biossistemáticos e filogenéticos em Copaifera L. (Leguminosae-Detarieae) com ênfase nas espécies do Brasil extra-amazônico. Tese de Doutorado. Universidade Estadual de Feira de Santana, Feira de Santana. 249p.

Dantas MM \& Silva MJ (2013a) O gênero Chamaecrista (Leguminosae, Caesalpinioideae, Cassieae) no Parque Estadual da Serra Dourada, Goiás, Brasil. Rodriguésia 64: 581-595.

Dantas MM \& Silva MJ (2013b) O gênero Senna Mill. (Leguminosae, Caesalpinioideae, Cassieae) no Parque Estadual da Serra Dourada, GO, Brasil. Hoehnea 40: 99-113.

Filgueiras TS, Nogueira PE, Brochado AL \& Guala II GF (1994) Caminhamento: um método expedito para levantamentos florísticos qualitativos. Cadernos de Geociências 12: 39-43.

Guida RS \& Teles AM (2015) Eupatorieae (Asteraceae) no Parque Estadual da Serra Dourada, Goiás, Brasil. Rodriguésia 66: 887-903.

Júnior JEC, Sodré RC, Silva MJ \& Sales MF (2013) Manihot (Euphorbiaceae s.s.) no Parque Estadual da Serra Dourada, Goiás, Brasil. Rodriguésia 64: 727-746.

Köppen W (1948) Climatologia: com um estudio de los climas de la Terra. F.C.E., Ciudad de México. 87p.

Lee YT \& Langenhein JH (1975) Systemetics of the genus Hymenaea L. (Leg. Caesalpinioideae, Detarieae). University of California Publications in Botany 69: 1-109.

Lewis GP, Schrire BD, Mackinder BA \& Lock M (eds.) (2005) Legumes of the world. Royal Botanic Gardens, Kew. 577p.

LPWG - The Legume Phylogeny Working Group (2013) Legume phylogeny and classification in the $21^{\text {st }}$ century: Progress, prospects and lessons for other species-rich clades. Taxon 62: 217-248.

LPWG - The Legume Phylogeny Working Group (2017) A new subfamily classification of the Leguminosae based on a taxonomically comprehensive phylogeny. Taxon 66: 44-77.

Moreira GL \& Teles AM (2014) A tribo Vernonieae Cass. (Asteraceae) na Serra Dourada, Goiás, Brasil. Iheringia, Série Botânica 69: 357-38.

Queiroz LP (2009) Leguminosas da caatinga. Feira de Santana. Universidade Estadual de Feira de Santana. 467p.

Rizzo JA (1970) Contribuição ao conhecimento da Flora de Goiás, área da Serra Dourada. Tese de Livre-docência. Universidade Federal de Goiás, Goiânia. 91p.

Silva MF (1986) Dimorphandra (Caesalpinioideae). In: Flora Neotropica. Vol. 2. The New York Botanical Garden, New York. 128p.

Sodré RCR \& Silva MJ (2014) Croton L. (Euphorbiaceae) no Parque Estadual da Serra Dourada, Goiás, Brasil. Rodriguésia 65: 221-234.

Thiers B [continuamente atualizado] Index Herbariorum: a global directory of public herbaria and associated staff. New York Botanical Garden's Virtual 
Herbarium, New York. Disponível em <http:// sweetgum.nybg.org/ih/>. Acesso em 1 abril 2016.

Trethowan LA, Clark RP \& Mackinder BA (2015) A synopsis of the neotropical genus Schnella (Cercideae: Caesalpinioideae: Leguminosae) including 12 new combinations. Phytotaxa 204: 237-252.
Vaz AMSF (2003) Flora dos estados de Goiás e Tocantins: Leguminosae Caesalpinioideae: Cercideae: Bauhinia. Vol. 30. Universidade Federal de Goiás, Goiânia. $121 \mathrm{p}$.

Vaz AMSF \& Tozzi AMGA (2003) Bauhinia ser. Cansenia (Leguminosae-Caesalpinioideae) no Brasil. Rodriguésia 54: 55-143. 